\title{
Representaciones sociales acerca de los microorganismos en estudiantes de Licenciatura en Biología*
}

Resumen: Como parte del trabajo de investigación doctoral en el campo de la resolución de problemas en una perspectiva de investigación en didáctica de la microbiología, se presenta una fundamentación conceptual de las representaciones sociales (RS), que en su conjunto tienen una función orientadora de la conducta de las personas en su vida cotidiana, y de las formas de organización y comunicación que se dinamizan en las relaciones interpersonales y entre los grupos sociales.

Se presentan resultados sobre detección de RS presentes en estudiantes de un programa de Licenciatura en Biología relacionados con la observación de microorganismos, mediante un cuestionario, observación no participante y análisis del registro de clase. El enfoque del trabajo es hermenéutico. El grupo con el cual se adelantó esta indagación está integrando por ocho estudiantes, entre los cuales cuatro cursaron microbiología previamente y cuatro no; todos ellos se encuentran en la mitad de la carrera.

Palabras clave: Representaciones sociales, cambio representacional, aprendizaje, microorganismo, observación, trabajo con el microscopio.

\author{
Rosalba Pulido de Castellanos** \\ Artículo recibido:21-02-2006 y aprobado:26-04-2006 \\ Social representations about microorganisms in \\ students of a biology \\ teaching program
}

Abstract: This study is part of the Doctoral research carried out on the field of problem solving and focused on didactics of microbiology teaching. The article presents a conceptual foundation of social representations (SR) that has to do with human behaviour in daily situations and with the organizational and communicative ways used to activate the interpersonal and social relation ships.

The results obtained in relation to the social representations among undergraduate students, are presented based on the instruments used to collect data: questionnaire, classroom observation and field notes. The population was comprised by eight students attending a biology program: four of them had previously taken the microbiology course and the other four had not.

Key words: Social representations, representational change, learning, microorganism, observation, microscopic work.

\footnotetext{
* Artículo basado en los resultados parciales de la tesis para optar al título de doctora en Educación, en el Área de Ciencias Naturales de la Universidad Pedagógica Nacional, Bogotá.

** Docente de tiempo completo, Departamento de Biología de la Universidad Pedagógica Nacional. Bogotá. rpulido@uni.pedagogica.edu.co
} 


\section{Introducción}

Un propósito de la educación en general y en ciencias en particular debería ser el de propiciar la potenciación de la persona, lo cual se dinamiza mediante actividades que posibiliten, entre otros procesos, el desarrollo de autonomía, metacognición y capacidad crítica en los educandos. Esto sólo es posible si se lo asume centrado en las personas, en sus dimensiones individuales y sociales. Ello implica generar condiciones que lleven a asumir posiciones críticas y proactivas en el campo de ejercicio profesional; además requiere involucrar en el currículo tres dimensiones que permitan apropiar el contexto y los retos del momento político, social y económico actual: la historicidad, la subjetividad y la intersubjetividad.

Específicamente, en el campo de la educación en ciencias, la potenciación del sujeto se vincula con el desarrollo de pensamiento crítico sobre la naturaleza de la disciplina o saber objeto de enseñanza escolar, en contexto. Involucra la reflexión sobre las condiciones de producción del saber y el análisis de su relación con el entorno, y el impacto sobre la sociedad, en el contexto local y nacional. Por tanto, trasciende el modo tradicional de enseñanza de las ciencias centrado en contenidos, al incorporar en el proceso de formación la reflexión histórica y epistemológica sobre la disciplina de estudio. Así, la educación en ciencias por la que se propende conlleva:

1) Afrontar tensiones entre los conocimientos acumulados en las disciplinas y saberes objeto de estudio y la construcción de sentido para los sujetos con quienes se realiza la interacción, de modo que los significados construidos por las respectivas comunidades académicas adquieran sentido y, por ende, sean incorporados críticamente al modo particular de ver el mundo por parte de cada uno de los estudiantes, y,

2) Contribuir a la formación de ciudadanos interesados en escudriñar y asumir una posición frente a las relaciones de la ciencia con los diferentes planos de la vida cotidiana (social, política, económica, ética y cultural).

Ello trasciende el interés -importante por cierto- de formar personas con inclinación hacia su desempeño como científicos. En este sentido, a la educación en ciencias en particular le cabe la responsabilidad de contribuir a cimentar procesos cognitivos y metacognitivos, procedimientales, actitudinales y valorativos, relacionados con el campo de las ciencias en el contexto en el que ellos se producen y con el establecimiento de las condiciones de validez y rigurosidad propias de las explicaciones científicas, al tiempo que se consideren las condiciones del contexto escolar en el que se realiza la interacción escolar.

Como un aspecto particular centrado en el caso de la enseñanza-aprendizaje de la biología, se presenta un estudio sobre las representaciones sociales acerca de los microorganismos, como fundamento de una propuesta didáctica en la que se pretende cimentar el desarrollo de metacognición y cambios en los modos de actuar en relación con estos organismos a partir de la consideración de las representaciones sociales, RS, como referente inicial del trabajo didáctico. Este estudio corresponde a la primera etapa de una investigación más 
amplia, relacionada con la didáctica de la microbiología a través de la resolución de problemas en una perspectiva de investigación. A diferencia del resto de seres vivos, la imposibilidad de observar los microorganismos a simple vista, así como su amplia diversidad biológica, llevan a que el trabajo didáctico en este campo sea un reto que implica trascender el nivel informativo para acceder a cambios de representaciones y, por tanto, de conocimientos, actitudes y referentes valorativos acerca de los microorganismos y su impacto en la naturaleza y en la sociedad, bien sea que se trate de microorganismos causantes de enfermedades, productores de compuestos empleados en la farmacología, la industria alimentaria, bioindicadores o de organismos con capacidad de descontaminar diversos ecosistemas y de vivir en condiciones extremas.

\section{Representaciones sociales}

Como parte del sistema de información y organización de maneras de interpretar el mundo, la información generada por diversos medios de expresión social -como la interacción familiar, la educación formal y la difusión mediática-, además de movilizar contenidos, propicia la difusión de valores, actitudes y comportamientos que de una u otra manera contribuyen a configurar los modos de interpretar el mundo, de asumir la interacción en lo social y con la naturaleza, al igual que las opciones que permiten la potenciación de los sujetos en el contexto en el cual se generan los saberes que hacen parte de la cultura del grupo social. Por consiguiente, es en el entramado de relaciones sociales donde se constituye el pensamiento intuitivo o la interpretación de sentido común, que también corresponde a lo denominado representaciones sociales del colectivo (RS), sentido común, pensamiento cotidiano o realismo ingenuo. $\mathrm{Al}$ tener en cuenta los procesos mediante los cuales se constituyen las RS y su fuerte arraigo con la intuición, es posible comprender que ellas constituyen significados y sentidos que se asumen como obvios y consistentes con experiencias empíricas, y por tanto forman parte del conjunto de explicaciones validadas por el grupo social; por ello las RS son referentes para la práctica social.

En las RS se consideran los contenidos cognitivos, afectivos y simbólicos, que en conjunto tienen una función orientadora de la acción de las personas en su vida cotidiana y de las formas de organización y comunicación que se dinamizan en las relaciones interpersonales y entre los grupos sociales. En consecuencia, se puede plantear que este tipo de conocimiento constituye el sistema de códigos, valores, lógicas clasificatorias, principios interpretativos y orientadores de las prácticas, que definen la conciencia colectiva, con carácter normativo, por cuanto determina los límites y las posibilidades de actuación humana (Araya, 2002). De acuerdo con Jodelet (1986), las RS se caracterizan por:

a) Ser elaboradas y compartidas socialmente.

b) Tener un fin práctico de organización del mundo (material, social y cultural) y de orientación de las conductas y de la comunicación.

c) Participar en el establecimiento de una visión de la realidad común a un grupo social o cultural determinado. 
Igualmente, es pertinente tener en cuenta que las RS se constituyen a través de:

a) Dos procesos formadores: la objetivación y el anclaje, y

b) Una esquematización que tiene como fin hacer una descripción, una explicación o una justificación (Moscovici, 1985).

El proceso de objetivación se refiere a la transformación de conceptos abstractos extraños en experiencias o materializaciones concretas (Jodelet, 1986). La objetivación se descompone en tres fases: la construcción selectiva, la organización de esquemas y la naturalización. La construcción selectiva de conceptos, teorías o ideas, que posteriormente son organizados libremente, se realiza en función de criterios culturales y normativos e implica retención. Se retiene sólo aquello que concuerda con el sistema de valores vigentes en un momento dado y de los que están en proceso de incorporación en el grupo social. De ahí que las informaciones con igual contenido sean procesadas diferencialmente por las personas.

La organización de esquemas tiene que ver con la tendencia de la RS a condensar o a abreviar, con la intención de comparar, catalogar y ordenar las imágenes y los contenidos, para generar una imagen simplificada y comprehensiva de lo objetivado. A su vez, los esquemas dan cuenta de la comprensión que las personas tienen, y son la base para el diálogo y el intercambio con los demás. El campo de representación se organiza en torno al esquema figurativo o núcleo figurativo. Este esquema o núcleo no sólo constituye la parte más sólida y más estable de la representación, sino que ejerce una función organizadora para el conjunto de la representación, pues es él quien confiere su peso y su significado a todos los demás elementos presentes en ella. A través del uso de los esquemas figurativos organizados en diferentes circunstancias, el contenido de la RS se convierte en un hecho natural, porque las imágenes remplazan lo percibido. Por ello se puede plantear que la naturalización dota a los componentes del esquema de una existencia concreta, material, observable y comprendida por todos; lo que se percibe no son ya las informaciones sobre los objetos, sino la imagen que remplaza y extiende de forma natural lo percibido: "Al sustituir los conceptos abstractos por imágenes, se reconstruyen esos objetos, se les aplican figuras que parecen naturales para aprehenderlos, explicarlos y vivir con ellos, y son esas imágenes las que finalmente constituyen la realidad cotidiana" (Araya, 2002).

Por su parte, el anclaje es el proceso mediante el cual los contenidos de la RS adquieren significado, pues se incorporan en la red de significados que posee la persona; es esencial para la constitución del pensamiento social e interviene al comienzo y al final de la formación de la representación (Moscovici, 1985). Así, el anclaje permite entender el proceso mediante el cual la RS interviene en la constitución de las relaciones sociales, pues su sentido se refiere a otros significados que rigen las relaciones simbólicas entre los miembros del grupo social; por tanto, el significado de una RS está siempre solapado o anclado en otros más generales que intervienen en las relaciones simbólicas propias de un campo social determinado (Doise, 1992). 
Por consiguiente, la interacción entre la objetivación y el anclaje permite comprender cómo lo social transforma los conocimientos y las acciones, y cómo estos conocimientos, una vez convertidos en RS, transforman la vida social. Abric (1996) considera que en las RS existe un núcleo central y elementos periféricos. El núcleo central es el componente principal y determina el significado de la representación como un todo; es estable, coherente, consensuado e influido por la memoria y los valores del colectivo; está vinculado a las creencias y normas de conducta, y por tanto se asocia con dimensiones no cognitivas. Los elementos periféricos están conformados por esquemas que se ubican entre las representaciones y la realidad'; éstos aseguran la concreción del núcleo central en la toma de posición y en el comportamiento. Un objeto hace parte de los intercambios si se vincula con la temática nuclear, la cual constituye de alguna manera el contenido "referencial" de la representación. El contenido vinculado posteriormente llega a ser constitutivo de las RS a través del anclaje. Las variaciones intersubjetivas de una misma representación pueden ocurrir justamente en este sistema periférico, generando así la posibilidad de una cierta individualización de dicha representación.

1 Se destaca que, desde la teoría de las RS, se asume la realidad socialmente construida; por tanto, en su construcción interactúan las dimensiones subjetivas, intersubjetivas y de contexto particulares a los grupos sociales. Estos aspectos son igualmente constitutivos de la producción científica, que también se consolida en las comunidades correspondientes, con sus propias condiciones de producción.
Del planteamiento anterior se deduce que las RS pueden presentar cambios en su significado, que pueden ser sutiles en la medida en que no afecten al núcleo central, o transformarse radicalmente si ocurre una modificación sustancial en el significado a nivel del núcleo central o temática canónica. En este sentido, se puede considerar que hay diversos tipos de modificación de las RS, que pueden implicar: una transformación superficial o de resistencia, en que sólo cambian los elementos periféricos; una transformación progresiva, que se presenta cuando el núcleo central se modifica por la integración de nuevos elementos sin ocasionar rupturas en los significados, y una transformación directa y completa, que se presenta cuando se producen modificaciones de fondo en su objetivación, anclaje y objetivación, generando cambios en el núcleo central, como consecuencia de las rupturas epistemológicas que se producen, lo cual, a su vez, contribuye al cambio de la realidad ontológica del sujeto (Marková, 1996).

Cabe anotar que, por su naturaleza, las teorías o modelos científicos son también representaciones socialmente generadas, y sus características de producción y validación en la comunidad científica correspondiente implican el desarrollo de abstracciones y relaciones que no necesariamente son evidentes en el mismo sentido en el cual se generan las RS a las que ha aludido como de sentido común. Por consiguiente, en los procesos educativos en el campo de las ciencias naturales, se requiere el desarrollo de razonamiento y condiciones de verificación de las explicaciones, diferentes de los procesos de constitución de las RS. Adicionalmente, puesto que en 
el aprendizaje de las ciencias se deben involucrar las actitudes y los comportamientos frente a los congéneres y a la naturaleza, además de los desarrollos conceptuales teórico-metodológicos propios de la disciplina o disciplinas relacionadas con un campo particular, el conocimiento acerca de las RS de los estudiantes es fundamental para contribuir a cimentar explicaciones consistentes con los conocimientos científicos, dando lugar a nuevas apropiaciones de la realidad y al desarrollo de capacidad crítica sobre la relación entre los desarrollos científico-tecnológicos y el contexto socio-cultural y las condiciones de producción y validación de la explicación científica.

\section{El trabajo con las rs en el ámbito escolar}

En los procesos de enseñanza-aprendizaje, el docente puede considerar las RS como una manera que le permita no sólo reconocerlas en su grupo de estudiantes, sino también evidenciar las implicaciones que tiene una explicación de sentido común acerca de un hecho o un proceso específico para el aprendizaje de las ciencias. Se trata de tenerlas en cuenta para trabajar a través de ellas, en el sentido propuesto por Giordan (1999), a fin de generar explicaciones provistas de nuevos sentidos y significados, coherentes con las científicas, de tal manera que se superen los obstáculos epistemológicos (Bachelard, 1975). Este punto es crucial si se tiene en cuenta que las RS son fuertemente arraigadas, pragmáticas y adaptativas; además, son útiles y eficaces en el ámbito cotidiano, en contraposición al pensamiento científico, que no es evidente y requiere abstracciones (Pozo, 1999).

Por consiguiente, las propuestas educativas tendientes a modificar una representación social pueden ser adecuadas si se orientan hacia la modificación del esquema figurativo, puesto que de él depende el significado global de la representación. Ello lleva a pensar que, para determinar una RS sobre un objeto o hecho específico, se requiere establecer qué se sabe (información), qué se cree, cómo se interpreta (campo de la representación) y qué se hace o cómo se actúa (actitud). Estas tres dimensiones, propuestas por Moscovici, forman un conjunto que tan sólo puede escindirse para satisfacer las exigencias propias del análisis conceptual (Araya, 2002). Desde esta perspectiva es posible considerar que el aprendizaje implica cambio representacional, es decir, emergencia de nuevas relaciones conceptuales y opciones de confrontación y contrastación de las implicaciones argumentativas que se redimensionan en el proceso, como resultado del desarrollo de una mirada cualitativamente diferente, producto del proceso individual en contexto de la interacción grupal, en determinadas condiciones socioculturales.

Consecuentemente con lo expuesto, aun cuando en el proceso de aprendizaje la nueva información presentada en desarrollo del proceso de enseñanza es relevante, ella por sí sola no es suficiente para propiciar el desarrollo de puntos de vista consistentes con la explicación científica, en los cuales, además de los desarrollos conceptuales propios de la disciplina estudiada, se dinamice lo procedimental, lo comportamental y lo 
axiológico. Se trata de la apropiación de un saber, que adicionalmente permita al estudiante un mayor conocimiento sobre sí mismo, dado que en su desarrollo se dinamizan procesos metacognitivos. Más aún, del trabajo centrado únicamente en la divulgación de conceptos no se deriva la posibilidad de asumir que la naturaleza del trabajo científico tiene ciertas características, como el hecho de que se trata de saberes históricamente construidos, con implicaciones sociales y culturales derivadas de su incidencia en el marco de los avances científicos, tecnológicos, económicos y ambientales.

Por otra parte, en el campo de la investigación didáctica, desde la década de 1980 se generó una amplia proliferación de trabajos en los que se buscó reconocer concepciones de los estudiantes en relación con diferentes temáticas (Carmichael et al., 1990; Hierrezuelo y Montero, 1991; Duschl, 1994); en ellos se encuentran propuestas metodológicas cualitativas, mediante las cuales se busca caracterizar el pensamiento de los estudiantes como base para la generación de propuestas didácticas tendientes a contribuir a la modificación de sus conceptos. Estas propuestas se centran en el cambio conceptual, como alternativa para una formación científica adecuada. Sin embargo, el desarrollo de trabajos posteriores muestra que centrar la atención en el cambio conceptual como fundamento del aprendizaje (Posner et al., 1982) tiene problemas de diferente orden, pues una educación en ciencias trascendente en la vida de los estudiantes presupone desarrollos que van más allá de la dimensión cognitiva (Campanario y Moya, 1999; Pozo, 2002).
Por ello Marín (2003) considera que el modelo de cambio conceptual ofrece una visión del aprendizaje parcial y errónea y su propuesta de enseñanza queda lejos de provocar el aprendizaje previsto, teniendo en cuenta que el conflicto cognitivo buscado puede generar modificaciones en los esquemas cognitivos ${ }^{2}$, en los cuales sólo se amplía la comprensión de contenidos de tal manera que se los asimila a los desarrollos científicos, pero los componentes procedimental, actitudinal y axiológico no son objeto de atención de la didáctica.

En el caso específico de la biología y de las ciencias naturales en general, se encuentra que:

a) Los profesores y estudiantes tienen representaciones sociales semejantes acerca de lo vivo (Fisher y Moody, 2000);

b) La revisión de cerca de 3000 publicaciones sobre concepciones relacionadas con la ciencia por parte de Wandersee (1985) permite afirmar que este tipo de explicaciones son compartidas por diferentes grupos sociales;

c) Igualmente las RS ofrecen explicaciones similares a las elaboradas por filósofos y científicos en épocas anteriores de la historia de la ciencia sobre los fenómenos naturales, y con gran frecuencia son actualmente

2 El término"esquema"surgió en el campo de la inteligencia artificial, como un constructo que intenta representar un escenario o contexto de la vida cotidiana en el cual adquiere sentido y a partir del cual se han generado diferentes posturas teóricas para explicar la modificación de los esquemas en contexto y tiempo determinados y representar este tipo de conocimientos mediante sistemas de inferencia lógicos (Gutiérrez, 2005). 
incorrectas a la luz de los conocimientos científicos vigentes ${ }^{3}$;

d) Tienen su origen en experiencias personales, que resultan de la observación directa y la percepción; son inconexas, pudiéndose evidenciar su carácter contradictorio (Pozo y Carretero, 1987).

e) Son muy resistentes al cambio, especialmente en condiciones de estrategias educativas tradicionales, dadas las dificultades que se enfrentan para sustituir conocimientos intuitivos ampliamente establecidos por argumentaciones racionales no necesariamente evidentes desde la observación empírica, como es el caso de los postulados científicos.

La propuesta de trabajar a través de las RS busca que cada estudiante asuma, de manera individual y en la interacción grupal, la reflexión sobre el significado y sentido de sus RS, sus alcances y limitaciones frente al conjunto de hechos o procesos explicados desde las ciencias, como parte del proceso de deconstrucción conceptual y de reflexión sobre las actitudes relacionadas con el objeto de estudio. Esta manera de abordarlas es un fundamento sólido para incentivar el desarrollo de aprendizaje autónomo y generador de nuevos significados para el estudiante, con base en la reflexión y la contextualización de las explicaciones, mediante un proceso de confrontación que posibilite, en una fase inicial, la coexistencia de explicaciones cotidianas y explicaciones acordes con los desarro-

3 El trabajo de Wandersee (1985) demuestra la importancia de relacionar la historia de la ciencia con los conceptos previos, para organizar la interacción escolar. llos del conocimiento científico (Fisher y Moody, 2000), y, paulatinamente, al enfrentar situaciones problemáticas, permita plantear soluciones acordes con los conocimientos científicos aun cuando se trate de ámbitos cotidianos, de tal manera que se evidencie la transformación de las RS por la constitución de conocimientos científicos.

Los elementos de análisis presentados hasta el momento permiten establecer que a través de las RS se puede contribuir, desde la enseñanza de las ciencias, al logro de un aprendizaje con sentido y, por tanto, transformador en los estudiantes. Se trata ahora de centrar la atención en un caso específico como lo es el de la microbiología.

\section{RS sobre los microorganismos y aprendizaje de la microbiología}

El trabajo acerca de las RS sobre los microorganismos ofrece retos interesantes en la enseñanza de la biología, por cuanto, además de las dificultades evidenciadas en su aprendizaje, existen otras adicionales relacionadas con el caso microbiano, teniendo en cuenta, por una parte, que se trata de seres imposibles de observar a simple vista, y por otra, las concepciones predominantes en los estudiantes acerca de lo vivo y lo no vivo (Díaz G. et al., 1996).

Sobre los problemas evidenciados en el aprendizaje de esta ciencia, llama la atención el trabajo de de Manuel et al. (1996), quienes investigaron acerca de las representaciones y dificultades comunes en la concepción del pensamiento biológico, llegando a algunas conclusiones relacionadas con este trabajo, de acuerdo con lo analizado por Rodríguez Palmero (1997): 
- Se detecta una aplicación errónea de la teoría celular al tamaño de los organismos.

- Es frecuente observar una representación plana de la célula originada por los esquemas y dibujos de los libros.

- Se enfatiza en el aprendizaje de los términos y no en la comprensión de los conceptos.

De ello se deduce que un reto de la didáctica de la biología en general, y de la microbiología en particular, tiene que ver con la posibilidad de generar explicaciones sobre los fenómenos objeto de estudio que "cuestionan" las RS derivadas del realismo ingenuo y los modos de representar los objetos propios del mundo tangible, para generar representaciones científicas que pueden ir contra toda evidencia del sentido común, o aun aquellas que ni siquiera son accesibles al realismo ingenuo, en contraste con la difusión mediática que generalmente relaciona a los microorganismos únicamente con el desarrollo de epidemias de diferente índole, tales como infecciones de tipo respiratorio como la neumonía aviar, la disentería o el cólera, o de otro tipo como la fiebre de las vacas locas; con el potencial empleo de algunos microorganismos como armas biológicas para ataques masivos a las poblaciones, como el caso del ántrax, y con diversos referentes al uso de jabones bactericidas, en la publicidad, como un procedimiento recomendable para mantener la piel sana y joven.

Estas informaciones de los medios de comunicación contribuyen a mantener ideas arraigadas acerca de los microorganismos única y exclusivamente como seres nocivos, lo cual hace imposible relacionarlos con el papel benéfico de muchos de ellos en los ecosistemas en los cuales habitan y su amplia aplicación tanto en la producción de alimentos, la agricultura, la industria cervecera, vinícola, química, como en procesos de biorremediación y descontaminación de ecosistemas industrializados, además de la influencia del trabajo con ellos en campos como la bioquímica, la biotecnología y la biología molecular.

De esa manera se constituye un conocimiento de los alumnos (Rodrigo et al., 1993; De Posada, 1996; Pozo y Gómez Crespo, 1998) en el que la interpretación de la relación de los microorganismos con el hombre y el entorno puede presentar componentes propios de las RS solapados con la información mediática sobre documentales científicos, asimilados por el individuo. "El lenguaje cotidiano interfiere con el lenguaje científico porque utiliza muchos términos científicos (hay que adaptarse a las circunstancias, iqué respiración más agitada!, agua de origen mineral...) con un significado bien distinto" (de Manuel y Grau, 1996). Así se configura una amalgama de explicaciones, cuya potencia explicativa y coherencia argumentativa deberían ser puestas a prueba en desarrollo de la interacción escolar, inducida por el profesor mediante las estrategias de enseñanza que considere apropiadas para tal efecto, con la intencionalidad de contribuir al desarrollo de un conocimiento que corresponda al aceptado por la comunidad científica en el campo de la microbiología, en el nivel de desarrollo pertinente para los estudiantes.

Por tanto, en el proceso de formación de docentes de biología es importante el 
desarrollo conceptual, procedimental, actitudinal y axiológico en relación con el mundo microbiano, como una opción para la generación de pensamiento crítico en lo relativo a estos organismos, el impacto que tienen en los diferentes escenarios en los que se encuentran y las condiciones ambientales en las que proliferan. Para que estos modos de explicación y actuación en relación con los microorganismos correspondan a los de la microbiología como ciencia es preciso afrontar el trabajo a través de las RS con las cuales llegan los estudiantes al curso, además de los desarrollos cognitivos acerca de la naturaleza biológica microbiana. Sobre este último aspecto, en el trabajo escolar con este grupo de organismos es importante considerar sus particularidades estructurales, fisiológicas, ecológicas y evolutivas, que llevan a la aplicación de métodos apropiados para el estudio de cada grupo microbiano; así, aun cuando en general se considera que el término microorganismo comprende a todos los organismos que tienen un tamaño inferior al del poder de resolución del ojo humano y se emplea el microcopio para su observación, esta característica no es un criterio definitivo que permita diferenciar los diversos grupos para establecer una clasificación fundamentada en sus propiedades estructurales, fisiológicas y genéticas.

Dentro de los grupos que hacen parte del mundo microbiano se incluyen los organismos arqueobacteriales, los procariontes y grupos de eucariontes, como son los hongos, las algas y los protozoos. Igualmente, en los textos de microbiología general se tratan los virus, aun cuando ellos son acelulares.
Sin embargo, el acercamiento al mundo microbiano se realiza inicialmente con los bacteriales, como grupo de organismos que comprende en la actualidad a los arqueobacteriales y a los procariontes. Una posible explicación puede ser el hecho de que en el desarrollo histórico del conocimiento acerca de los microorganismos, las explicaciones sobre su naturaleza biológica y los métodos de trabajo correspondientes se generaron a partir del trabajo bacteriano relacionado con la elaboración de productos de la actividad de estos organismos (como el vino, la cerveza y el vinagre), con la determinación de la etiología de las enfermedades infecciosas, con la demostración de la ubicuidad de los microorganismos y la evidencia de gran variedad de estrategias metabólicas presentes en ellos.

Respecto a la observación microscópica de material biológico, Díaz de Bustamante y Jiménez (1996) detectaron ideas previas sobre la observación de muestras de material biológico como frotis de la mucosa bucal, epitelio de cebolla y epidermis de hojas de lirio, en alumnos de secundaria y universitarios. Destacan que la cantidad y calidad de dibujos de las estructuras observadas es mayor, cuando esta actividad es posterior a la elaboración de dibujos sobre las ideas previas que los estudiantes tienen respecto a la estructura celular. Sin embargo, estas representaciones gráficas son bastante pobres frente a la cantidad de estructuras que podrían diferenciarse en las condiciones de trabajo en las cuales se realiza la práctica. Igualmente, evidencian tres tipos de dificultades en los estudiantes: actitudinales, de destrezas técnicas 
y dependientes de las habilidades de observación del estudiante:

1) Al primer tipo, corresponde el interés por el trabajo en general y por la elaboración del dibujo correspondiente, que es realizado de manera superficial y rápida para cumplir con la tarea;

2) Se pueden atribuir complicaciones derivadas de la técnica de preparación del material para su observación y al manejo adecuado del microscopio (iluminación, enfoque), y,

3) Incapacidad para interpretar imágenes. Esta última dificultad tiene que ver con la posibilidad de: discriminar formas del fondo, realizar inferencias de lo observado, aspecto en el cual inciden los conocimientos y experiencias anteriores sobre el material objeto de trabajo (características del material en lo relacionado con los contornos celulares, el contraste que se establece entre la célula -sea ella de material vegetal o animal- y el tipo de tejido seleccionado, y la interpretación de estructuras tridimensionales percibidas en la observación microscópica como bidimensionales).

En el caso del trabajo con los microorganismos, y particularmente con material bacteriano, los anteriores aspectos son de la mayor importancia, pues el tamaño celular es considerablemente más reducido que el material trabajado en la investigación de Díaz de B. y Jiménez (1996). Por otra parte, en algunos libros de texto la manera como se trabajan algunos temas que tienen que ver con los microorganismos podría estar relacionada con errores como es el caso de fermentación, conservación de alimentos (Díaz, G. et al., 1996), etiología de las enfermedades infecciosas y transformaciones de la materia inducidas por microorganismos. Por otra parte, como un aspecto particular de las RS acerca de los microorganismos, surge la cuestión sobre la manera como los estudiantes los representan de manera gráfica. Este aspecto constituye una faceta valiosa de indagación: se relaciona con la manera como se asume desde lo visual la interpretación de organismos que, por su tamaño, no son visibles directamente y que, por tanto, para su observación deben emplearse microscopio y colorantes, a fin de diferenciar las formas celulares, de residuos u otros materiales presentes en un micropreparado.

Teniendo en cuenta los planteamientos anteriores, es preciso profundizar en las características de las RS acerca de los microorganismos, como punto esencial en el trabajo didáctico encaminado a su transformación. En este sentido, el problema que orienta esta parte de la investigación se especifica mediante la pregunta: ¿Qué características presentan las RS acerca de los microorganismos presentes en estudiantes que se forman como docentes en biología y que se encuentran cursando la mitad de su programa de estudios?

\section{Metodología}

La investigación es de carácter cualitativo, relacionada con la corriente de estudio de Jodelet sobre las RS, en la cual se considera que los procesos mentales individuales y las interacciones grupales inciden en su configuración. El estudio de las RS involucra la recolección, el análisis cualitativo de datos y la triangulación, para profundizar en las explicaciones 
y las actividades a través de las cuales ellas se producen o se aplican, como conjunto de elementos constituidos y estructurados, y como pensamiento social constituyente (Banchs, 2000). Puesto que se busca establecer aspectos cognitivos, procedimentales y actitudinales acerca de los microorganismos, presentes en el grupo de estudiantes al inicio del curso, se aplicaron cuestionarios, análisis del registro de clase y observación no participativa, como instrumentos para recolección de información para la caracterización de las RS sobre los microorganismos, presentes en estudiantes de un programa de formación como docentes de biología, a partir de una exploración basada en observación de muestras de agua y suelo. Para ello, las cuestiones examinadas fueron:

1. ¿Qué ideas iniciales tienen los estudiantes sobre las muestras que van a observar?

2. ¿De qué manera interpretan las observaciones que realizan?

3. ¿Cómo explican lo observado?

La información recolectada se trabajó mediante análisis de contenido teniendo en cuenta que se hace énfasis en el aspecto constituyente de las RS (Araya, 2000). Involucra el análisis del texto elaborado por los estudiantes acerca de los temas planteados en un cuestionario (anexo 1), que están estrechamente relacionados con el sentido en el que se emplean términos de la microbiología por parte de los estudiantes; igualmente se recurrió a la elaboración de diagramas como resultado de la observación microscópica, en los que se centró la atención sobre los elementos constitutivos de los diagramas. La recolección de información se complementó con la ficha de registro de clase, la cual se adelantó mediante observación no participante, realizada durante el desarrollo de la actividad. Así, el punto central del análisis está en la interpretación de la elaboración de cada uno de los estudiantes del estudio, en la comparación de resultados entre todos ellos, acerca de una misma cuestión, y en el establecimiento de relaciones entre los aspectos involucrados en las explicaciones presentadas, buscando describir y explicar las RS detectadas. Es preciso destacar que en la investigación reportada en este artículo se centró la atención en aspectos cognitivos y procedimentales, que se complementan en otras etapas de la misma, en las que se buscó reconocer actitudes de los estudiantes relacionadas con el trabajo con los microorganismos y las interacciones entre ellos y el hombre.

Cabe anotar que de los participantes, cuatro estudiantes cursaron previamente Microbiología General y otros cuatro no, aun cuando ambos grupos ya habían sobrepasado la mitad de la carrera. Es decir, todos los estudiantes ya habían tenido contacto con la observación microscópica, lo cual no significa necesariamente que hubieran desarrollado las habilidades técnicas requeridas para el trabajo con el microscopio, con lo cual se corrobora una de las dificultades enunciadas por Díaz de Bustamante y Jiménez (1996).

\section{Resultados y análisis de resultados 5.1 Observación microscópica}

El tipo de pregunta hace referencia al tipo de explicaciones que presentan los estudiantes y su consistencia con aquellas propias del campo disciplinar. 
Ante la pregunta: ¿Qué espera detectar al observar muestras de agua o de suelo al microscopio?, se pretendió que los estudiantes presentaran un panorama de qué tipos de organismos pueden ser observados con el uso del microscopio compuesto, a partir de un montaje in vivo. Las respuestas de los estudiantes se presentan en la tabla 1, organizada en los dos grupos enunciados.

Puesto que se trata de información obtenida al inicio del curso, lo planteado por los estudiantes corresponde tanto a conceptos o ideas retenidas como a los esquemas que hacen parte del proceso de constitución de las RS, lo que a su vez permite profundizar acerca de la caracterización de su pensamiento y establecer si se trata de aproximaciones intuitivas o rigurosas, según se las presente. Por tanto, la interpretación que se deduce de cada respuesta está centrada en la detección de conceptos y sentidos expresados por cada estudiante acerca de la cuestión.

\begin{tabular}{|c|c|c|}
\hline \multicolumn{3}{|c|}{ GRUPO 1 (Ya han cursado microbiología) } \\
\hline Cód. & Respuesta & Comentario \\
\hline AYO & $\begin{array}{l}\text { "Protozoarios, invertebrados, re- } \\
\text { presentantes del reino mónera, } \\
\text { colonias o micelios de hongos } \\
\text { y algunas simbiosis o interre- } \\
\text { laciones de tipo ecológico no } \\
\text { sólo entre estos organismos, } \\
\text { sino en el medio en que se está } \\
\text { observando". }\end{array}$ & $\begin{array}{l}\text { Se destaca el uso de términos propios del lenguaje biológico, pero } \\
\text { aparecen descontextualizados teniendo en cuenta que se trata de } \\
\text { observación de alícuotas de agua estancada o de dilución de suelo, } \\
\text { que se preparan directamente de la muestra en el portaobjeto; por } \\
\text { tanto, no da a lugar la consideración de observación de colonias de } \\
\text { hongos o de relaciones ecológicas en este tipo de trabajo práctico. } \\
\text { Se podría considerar que aun cuando hay información, ella no está } \\
\text { sistematizada de manera organizada en un cuerpo explicativo } \\
\text { articulado. }\end{array}$ \\
\hline NLR & $\begin{array}{l}\text { "Detectar bacterias, pueden ser } \\
\text { cocos o diplococos, gran canti- } \\
\text { dad de protozoarios y rotíferos, } \\
\text { que son organismos que viven } \\
\text { en agua estancada. Algas, pue- } \\
\text { den ser pardas y clorofíceas". }\end{array}$ & $\begin{array}{l}\text { Pese a que se emplean términos biológicos y se puede deducir } \\
\text { el conocimiento de diferentes tipos bacterianos, la observación } \\
\text { bacteriana in vivo es difícil, pues se requiere un entrenamiento que } \\
\text { permita evidenciar, mediante contraste de iluminación y de enfo- } \\
\text { que, la presencia de bacterias; en el caso de las algas se presenta } \\
\text { un error al asumir que en agua estancada, que por las caracterís- } \\
\text { ticas del trabajo es agua dulce, se puedan encontrar algas pardas. } \\
\text { Se destaca el hecho de que un grupo de algas se nombra con el } \\
\text { término biológico -clorofíceas-, mientras que en el otro caso no } \\
\text { se denomina feofíceas a las algas pardas; ello podría interpretarse } \\
\text { como un uso descuidado del lenguaje, pero a su vez sería un indicio } \\
\text { de que el manejo indistinto de la terminología puede estar ligado } \\
\text { a falta de rigurosidad conceptual; solamente con la confrontación } \\
\text { de resultados obtenidos en otras pruebas sería viable reforzar esta } \\
\text { idea o, por el contrario, desecharla. }\end{array}$ \\
\hline ASR & $\begin{array}{l}\text { "Se espera observar en mues- } \\
\text { tras de agua, microorganismos } \\
\text { como protozoos (paramecium, } \\
\text { euglenas), algas (diatomeas), } \\
\text { ya que son los organismos que } \\
\text { habitualmente se encuentran } \\
\text { en aguas estancadas". }\end{array}$ & $\begin{array}{l}\text { Se deduce que esta persona tiene información y conoce termi- } \\
\text { nología propia del mundo microbiano, específicamente de los } \\
\text { protistos, pero no demuestra un manejo organizado de los mismos, } \\
\text { por cuanto las euglenas hacen parte del grupo de organismos que } \\
\text { se reconocen como algas, aun cuando tengan estructuras que les } \\
\text { permiten moverse, de manera similar a como lo hacen algunos } \\
\text { protozoos que son flagelados, pues por poseer cloroplastos, tienen } \\
\text { capacidad de realizar fotosíntesis. }\end{array}$ \\
\hline
\end{tabular}




\begin{tabular}{|c|c|c|}
\hline Cód. & Respuesta & Comentario \\
\hline APN & $\begin{array}{l}\text { "Basándonos en prácticas de } \\
\text { este tipo realizadas ante- } \\
\text { riormente, espero observar } \\
\text { protozoos, más específicamen- } \\
\text { te euglenas, algunas algas y } \\
\text { paramecios". }\end{array}$ & $\begin{array}{l}\text { Por la manera como redactó la respuesta, en este caso se pudo } \\
\text { incurrir en una ligereza al reunir las algas como protozoos. Sin em- } \\
\text { bargo queda la inquietud de hasta qué punto este tipo de expresio- } \\
\text { nes son "descuidos de escritura"y no el reflejo de dificultades de } \\
\text { conceptualización sobre la clasificación de estos organismos. Si esta } \\
\text { última impresión se ratifica en posteriores pruebas, ello da cuenta } \\
\text { de una respuesta basada en información memorística y no nece- } \\
\text { sariamente en aplicación de conceptos asimilados como resultado } \\
\text { del proceso de aprendizaje anterior, sobre estos organismos. }\end{array}$ \\
\hline
\end{tabular}

\begin{tabular}{|c|c|c|}
\hline \multicolumn{3}{|c|}{ GRUPO 2 (No han cursado microbiología) } \\
\hline Cód. & Respuesta & Comentario \\
\hline ARC & $\begin{array}{l}\text { "Formas de vida como organismos } \\
\text { flagelados, hongos, que a simple } \\
\text { vista no podrían ser observados." }\end{array}$ & $\begin{array}{l}\text { Es evidente que esta persona tiene información sobre algunos } \\
\text { tipos de organismos que se pueden encontrar, pero pudiera } \\
\text { pensarse que no tiene experiencia anterior de trabajo con } \\
\text { hongos, puesto que para la observación de estos organismos } \\
\text { se requiere el empleo de colorantes, pues en general el micelio } \\
\text { de los hongos es hialino (transparente). }\end{array}$ \\
\hline ACB & $\begin{array}{l}\text { "Espero detectar algunos micro- } \\
\text { organismos que por su tamaño } \\
\text { no se encuentran visibles sin un } \\
\text { microscopio; además de encontrar } \\
\text { algunas algas y diversas formas de } \\
\text { ellas. A su vez, reconocer estructuras } \\
\text { y tamaños de acuerdo con lo que } \\
\text { algunos textos muestran". }\end{array}$ & $\begin{array}{l}\text { La expresión "no se encuentran visibles" sin un microscopio } \\
\text { llama la atención por cuanto genera la pregunta de si el hecho } \\
\text { de no verlos implica la existencia de microorganismos visibles } \\
\text { a simple vista. Esta implicación es consistente con los desa- } \\
\text { rrollos actuales de la Microbiología. Por otra parte, es el único } \\
\text { caso en el que se plantea una expectativa referida al reconoci- } \\
\text { miento que trasciende al grupo microbiano y busca establecer } \\
\text { tanto relaciones de tamaño como observación de estructuras } \\
\text { de los organismos. }\end{array}$ \\
\hline $\mathrm{DCH}$ & $\begin{array}{l}\text { "Espero detectar diferentes tipos de } \\
\text { microorganismos". }\end{array}$ & $\begin{array}{l}\text { Por lo sucinto de la respuesta, en este caso, se podría inter- } \\
\text { pretar que la persona cumplió con escribir algo para hacer la } \\
\text { tarea. }\end{array}$ \\
\hline MIB & $\begin{array}{l}\text { "Microorganismos que posible- } \\
\text { mente sean bacterias... Diferentes } \\
\text { clases de microorganismos que se } \\
\text { han identificado a partir de los de- } \\
\text { sarrollos tecnológicos y científicos". }\end{array}$ & $\begin{array}{l}\text { Aun cuando, en un primer momento, se trata de una respues- } \\
\text { ta que sugiere el cumplimiento de una tarea, la explicación } \\
\text { posterior es un intento de profundizar en la respuesta, que en } \\
\text { todo caso no permite una aproximación a las explicaciones } \\
\text { que lleven a dilucidar sus expectativas. }\end{array}$ \\
\hline
\end{tabular}

Tabla 1. Resultados de la observación microscópica.

La comparación de las respuestas de los estudiantes hace posible aseverar que, aunque se detecta algún grado de información sobre el mundo microbiano, no hay evidencia de desarrollos conceptuales coherentes con los desarrollos propios de la microbiología relacionados con la clasificación de los grandes grupos microbianos, por cuanto se presentan confusiones acerca de sus carac- terísticas; ello puede indicar que, pese al proceso de interacción adelantado en los semestres anteriores, los estudiantes conservan las explicaciones intuitivas, con alguna adición de términos propios de la disciplina. Lo anterior se refuerza ante aquellas respuestas en que se alude a características de los organismos vinculadas con relaciones ecológicas de diferente índole, que trascienden la 
observación directa. En un primer nivel de interpretación, estos hallazgos son consistentes con los planteamientos de Marín (2003) a propósito de los conocimientos del alumno, en los cuales "tanto el conocimiento académico de ciencias a enseñar como el adquirido por el alumno en este ámbito pueden variar notablemente", en la medida en que en las respuestas se encuentran conocimientos implícitos que es preciso develar mediante otras estrategias de indagación.

En el proceso de indagación adelantado, se previó que a partir de las pregun- tas 2 y 3 se lograra recabar información acerca de la interpretación del material observado bajo el microscopio.

\subsection{Naturaleza de la observación y trabajo práctico}

Este aspecto se indagó mediante las preguntas 2 y 3 del cuestionario, cuyas respuestas, para efectos del análisis, se presentan consecutivamente en cada uno de los estudiantes participantes. En la tabla 2 se presentan el resultado y los comentarios correspondientes a las respuestas de cada uno de los estudiantes.

\section{GRUPO 1. (Ya cursaron microbiología)}

\begin{tabular}{|c|c|c|}
\hline Cód. & Respuesta & Comentario \\
\hline AYO & $\begin{array}{l}\text { 2."Si al hacer la revisión bibliográ- } \\
\text { fica previa y posterior encuentro } \\
\text { aciertos y similitudes tanto en su } \\
\text { morfología como a nivel ecológi- } \\
\text { co. Otra posibilidad es la discusión } \\
\text { y comparación de resultados con } \\
\text { mis compañeros. } \\
\text { 3. Fuente de información es la re- } \\
\text { ferencia bibliográfica y el Internet, } \\
\text { pero por otro lado la experiencia } \\
\text { ya vivida en el curso anterior, del } \\
\text { quinto semestre. }\end{array}$ & $\begin{array}{l}\text { Hay consistencia con la respuesta del punto anterior en la } \\
\text { medida en que se asume la dimensión ecológica; sin embargo, } \\
\text { puesto que se trata de observación microscópica de muestras de } \\
\text { agua o de solución de suelo, ello no es pertinente para este caso. } \\
\text { Adicionalmente, se involucra el trabajo grupal como una fuente } \\
\text { de confrontación de la información y la experiencia anterior del } \\
\text { trabajo práctico. } \\
\text { No se presentan elementos de análisis relacionados con carac- } \\
\text { terísticas morfológicas. Por otra parte, la alusión a que la fuente } \\
\text { de información es la bibliografía e Internet, no hay elementos de } \\
\text { análisis que permitan relacionar esta respuesta con desarrollos } \\
\text { propios del estudiante, que a su vez remitan a la consideración } \\
\text { de sus RS al respecto. }\end{array}$ \\
\hline NLR & $\begin{array}{l}\text { 2.“Por medio de observación de } \\
\text { muestras en el microscopio para } \\
\text { determinar la presencia de algas y } \\
\text { bacterias esencialmente". } \\
\text { 3."La fuente de información es la } \\
\text { observación al microscopio y los } \\
\text { libros especializados en el tema } \\
\text { de algas, bacterias." }\end{array}$ & $\begin{array}{l}\text { Se destaca el hecho de que se involucran solamente algas y } \\
\text { bacterias en el reconocimiento, cuando en este tipo de práctica } \\
\text { es más frecuente la observación de algas, animales microscópi- } \\
\text { cos y protozoos. Hay tautología en la manera como considera el } \\
\text { cumplimiento de sus expectativas, lo que permitiría aludir a un } \\
\text { predominio de razonamiento intuitivo; cabe la cuestión acerca } \\
\text { del propósito con el cual se consultarían los libros especializa- } \\
\text { dos sobre estos organismos, dado que en este tipo de textos es } \\
\text { posible encontrar gran cantidad de microfotografías electrónicas, } \\
\text { análisis molecular, taxonomía o caracterización ultraestructural. }\end{array}$ \\
\hline ASR & $\begin{array}{l}\text { 2."Encontrar dichos organismos y } \\
\text { una identificación de lo obser- } \\
\text { vado". } \\
\text { 3."Fuente de información: biblio- } \\
\text { grafía". }\end{array}$ & $\begin{array}{l}\text { Como no expresa de qué manera evidencia el encontrar dichos } \\
\text { organismos, resulta una respuesta que puede asimilarse al } \\
\text { razonamiento intuitivo; sin embargo incluye la comprensión de la } \\
\text { observación y su relación con el medio, establece relaciones en- } \\
\text { tre diferentes aspectos relacionados con el objeto de trabajo, lo } \\
\text { cual apoyado en la bibliografía, y permite distanciar esa reflexión } \\
\text { inicialmente planteada de la sola intuición. }\end{array}$ \\
\hline
\end{tabular}




\begin{tabular}{|c|c|c|}
\hline Cód & Respuesta & Comentario \\
\hline APN & $\begin{array}{l}\text { 2."Ya que el objetivo de las muestras es observar algunos } \\
\text { microorganismos, con el hecho de poder evidenciarlos } \\
\text { y llegar a una aproximación de ¿qué son? Ya con estos } \\
\text { parámetros puedo alcanzar las expectativas en la } \\
\text { observación. Se debe hacer un reconocimiento del } \\
\text { organismo con lo aprendido hasta el momento junto con la } \\
\text { bibliografía". } \\
\text { 3."La fuente de información puede estar dada por la } \\
\text { bibliografía en los libros como microbiologías y claves } \\
\text { taxonómicas". }\end{array}$ & $\begin{array}{l}\text { Surge la siguiente cuestión: } \\
\text { ¿Cómo llegar a evidenciar } \\
\text { fehacientemente que lo observado } \\
\text { son microorganismos, ubicados en } \\
\text { el grupo de los protistos, monera o } \\
\text { animales microscópicos y no restos } \\
\text { de material vegetal? Este punto se } \\
\text { complementa con la referencia a la } \\
\text { bibliografía. }\end{array}$ \\
\hline
\end{tabular}

\begin{tabular}{lll}
\hline \multicolumn{3}{c}{ GRUPO 2. (No han cursado Microbiología) } \\
\hline Cód & Respuesta & Comentario \\
\hline
\end{tabular}

"Debo tener claridad en mi observación, realizar gráficas claras que me permitan contrastar con la

ARC bibliografía, si lo que observe sea realmente algún tipo de microorganismo."'La cuestión es cómo tener claridad en la observación?"
Ello se relaciona con la reflexión necesaria en el trabajo científico experimental sobre la naturaleza misma de la observación.

2."Haciendo gráficas y descripciones de lo observado y verificar bibliográfica y colectivamente con mis compañeros los resultados, para que a partir de esa discusión, se pueda hacer un balance de lo realizado. A su vez, al verificar que la metodología que estoy llevando a cabo me permite alcanzar un aprendizaje

ACB significativo en torno al conocimiento de los microorganismos".

3."Lo primero es el conocimiento que hasta el momento puedo tener acerca de la materia y los análisis que puedo llegar a realizar con respecto a la observación; también la revisión posterior a la observación es fundamental para contrastar los resultados".

Se dimensiona el trabajo individual, la discusión grupal y la confrontación bibliográfica como base del aprendizaje sobre el reconocimiento microbiano. Hace alusión a lo metodológico, que es un aspecto no considerado por los demás estudiantes.

2."Antes de realizar la observación se debe tener la noción de qué es lo que se va a observar; por ello es primordial tener un referente teórico el cual pueda ser demostrable en la práctica"'Las metas propuestas antes de empezar la práctica serán satisfechas si se logran evidenciar, reconocer, distinguir los diferentes microorganismos que se encuentren en las muestras de suelo o agua, comparándolas con las bases teóricas consultadas anteriormente".

3. Libros de microbiología, tesis que hablen del tema.

2. “Cuando se haga una comparación en el material bibliográfico y algunas discusiones acerca de la temá-

MIB tica propuesta".

3."Los libros y videos que hablen de biología general y de las disciplinas que la apoyan".

Este es el único caso en el que se alude directamente a la necesidad de contar con referentes teóricos. Ello es consistente con planteamientos de Canguilhem (1971) acerca de que "el microscopio, más que la prolongación de los ojos, es la prolongación de la mente". Sin embargo, la alusión a las tesis no es clara, en la medida en que en estos trabajos se abordan problemas específicos de investigación, mientras que en la práctica en la que se contextualiza este cuestionario se trata de una observación de muestras de agua o de solución de suelo que puede permitir una amplia variedad de organismos.

Se presenta un caso en el cual, además de la revisión bibliográfica, se incluye la discusión, lo cual puede ayudar a confrotar puntos de vista y a profundizar en la realidad de las argumentaciones; no se considera la revisión de textos o revistas especializadas.

Tabla 2. Resultado y los comentarios correspondientes a las respuestas de cada uno de los estudiantes. 
En este caso, casi todos los estudiantes consideran que la revisión bibliográfica es la base para evidenciar el logro de las expectativas de la observación. Sin embargo, cabe resaltar la inquietud por el interés en la bibliografía en la medida en que, durante la sesión de trabajo, los libros se emplearon para buscar diagramas o fotografías semejantes a los especímenes que encuentran en el material que observan al microscopio. De esta manera la observación, más que estar basada en la reflexión, está acompañada de la analogía y comparación con dibujos o fotografías que permitan establecer similitudes entre el material registrado en el texto y el que se encuentra en el micropreparado. A lo anterior se agrega el problema del tipo de fotografía de los textos, que frecuentemente se realiza sobre especímenes procesados mediante técnicas microscópicas especiales como el contraste de fase, el campo oscuro o fluorescencia, entre otras. Cabe entonces la cuestión de si efectivamente se trata de generar conceptualizaciones o explicaciones sobre las características de los organismos observados, o solamente el trabajo se queda en un nivel inicial de "ver" y relacionar aquello que se observa con un nombre por su semejanza; una posible explicación para esta situación apunta a la dificultad de la percepción de objetos microscópicos, resultado de la interacción en el mundo macroscópico, que lleva a "pensar en los microbios no sólo con una configuración similar a los organismos visibles, sino incluso con cualidades antropomorfizadas" (Díaz et al., 1996).

En síntesis, como resultado de esta indagación se encuentra que para el grupo en general, los textos se constituyen en referente de certeza sobre la observación que se realiza; ello lleva a la necesidad de corroborar si se trata de una situación ligada directamente con la "visualización de formas y organización" semejantes a las que se ilustran en los textos o, por el contrario, si ello resulta de la idea de que en los textos de ciencias está la verdad. Este punto es importante para el análisis de las RS presentes en los estudiantes, pues tiene arraigo en la posición epistemológica de cada uno y, por tanto, se relaciona con aspectos que hacen parte del núcleo central de las RS acerca de la naturaleza de las ciencias y el modo como se desarrolla el trabajo científico. Sin embargo, de las anteriores preguntas no es posible establecer claramente una caracterización al respecto.

Por otra parte, la variedad de respuestas a las cuestiones planteadas pone de presente la necesidad de profundizar sobre las redes de relaciones conceptuales y los desarrollos procedimentales de cada uno de los estudiantes, pues es claro que aun cuando hay puntos comunes en la manera como se asume el trabajo de observación, también hay diferentes posicionamientos; de esta manera se confirma lo planteado en la bibliografía sobre la pertinencia de aplicar diferentes estrategias para evaluar el conocimiento de los estudiantes, caracterizar sus RS y generar estrategias de aprendizaje con posibilidad de trascender el plano informativo.

Adicional a lo anterior, la revisión de la observación microscópica fue realizada teniendo en cuenta los dibujos elaborados por cada estudiante en sus apuntes. Para cada uno de los aumentos del lente objetivo del microscopio, se detalló el modo de representar gráficamente lo observado. En este caso es importante tener presente el conoci- 
miento procedimental de los estudiantes para realizar un montaje adecuado de la preparación y el enfoque correcto del microscopio en cada uno de los aumentos. Se trata de conocimientos específicos para el trabajo de microscopía. La información detectada durante la sesión de trabajo se complementó con preguntas sobre las razones por las cuales se realizaba determinada acción de manipulación o acerca del dibujo realizado como resultado de lo observado.

Por las características morfológicas y ante el hecho de que algunos estudiantes ya habían trabajado en un curso anterior con microorganismos, se reconocen con mayor facilidad las algas. Sin embargo, en el dibujo correspondiente no se presentan detalles sobre la estructura o sobre la morfología celular que se pueden apreciar con el microscopio óptico, en las condiciones del laboratorio en el que se realizó la práctica. Ello contribuye a corroborar la descripción de las RS que los estudiantes presentan sobre los microorganismos, en las cuales las opiniones prevalecen sobre las conceptualizaciones, pues aun cuando puede haber planteamientos relacionados con la estructura celular, por ejemplo en el caso de las algas, al observar el material in vivo y hacer el dibujo, no hay una relación entre la información y la búsqueda por los orgánulos o estructuras internas, ni tampoco la formulan cuestionamientos a la docente o la monitora al respecto.

Los anteriores aspectos ponen de manifiesto la necesidad de acometer modelos alternativos a los tradicionales para trabajar desde las RS detectadas en los estudiantes, de tal manera que se supere la idea generalizada de una enseñanza centrada en los contenidos. Así, el reto de propiciar el cambio en las explicaciones de los estudiantes, de manera que se fundamente la capacidad argumentativa consistente con los desarrollos científicos, requiere trabajar contando con los referentes de los estudiantes. Por ello el desarrollo de la capacidad argumentativa es un medio para evidenciar la comprensión y capacidad de establecer relaciones entre diferentes conceptos y métodos, lo cual, a su vez, hace parte de los propósitos que se buscan a través de la educación en ciencias.

\section{Conclusiones}

Como puntos necesarios por concretar en otras etapas de la investigación, en las respuestas y en los registros de clase correspondientes se presentan algunas de las conclusiones relevantes al campo de las RS, evidenciadas. Se detecta un bajo nivel de conocimientos relacionado con las características de los microorganismos, pues prevalecen respuestas sin argumentación consistente y más bien producto de informaciones desorganizadas y memorizadas, así se empleen términos propios del lenguaje microbiológico. Ello permite aseverar que al inicio del trabajo las RS de los estudiantes, relacionadas con aspectos cognitivos sobre los microorganismos, están alejadas de las explicaciones de la disciplina: se detecta una concepción pobre sobre la naturaleza de los microorganismos y su estructura celular, y en los diagramas se refleja una interpretación de los organismos como planos y no como entes tridimensionales.

Por consiguiente, es preciso tener en cuenta que si no se plantean procesos educativos desde posturas teóricas ex- 
plícitas, que fundamenten el ejercicio de clase orientado hacia aprendizajes con sentido científicamente aceptable, es posible desarrollar muchas actividades, pero ellas resultan inadecuadas; ello se evidencia al comparar los resultados de las apreciaciones de ambos grupos: en estudiantes que tuvieron una aproximación intensiva al trabajo con los microorganismos, hay representaciones comparables a las de los estudiantes que no han tenido esa experiencia escolar.

Se destaca la persistencia de explicaciones inadecuadas, a pesar de que reconocen experiencias anteriores. Se puede inferir, sin embargo, que en estudiantes que aún no han cursado microbiología general, hay expresiones que permiten pensar que se han hecho reflexiones acerca de la naturaleza de la observación. Esta circunstancia es relevante al tener en cuenta que se trata de estudiantes que están ubicados en un plan de estudios en el que se busca una reflexión en torno a la naturaleza de las ciencias, pero se requiere profundizar en la naturaleza de las RS, en la perspectiva de organizar las actividades de enseñanza a través de ellas, para contribuir al desarrollo de pensamiento, actitudes y valores consecuentes con los desarrollos que se busca generar en la educación en ciencias.

Como resultado de esta investigación es preciso anotar que partir desde la detección de las RS de los estudiantes para afrontar el proceso de enseñanza-aprendizaje es un paso inicial para abordar la interpretación correspondiente, de manera que se contribuya a su transformación al constituirse en núcleo central explicativo coherente con las explicaciones científicas en el contexto actual y, por tanto, en la perspectiva de la provisionalidad y dinámica de la producción científica. $\Delta$

\section{ANEXO 1 \\ TRABAJO PRÁCTICO \\ RECONOCIMIENTO DE MICROORGANISMOS}

Se presenta una indagación inicial general que es base para la organización de algunas actividades de laboratorio.

Agradezco especialmente la respuesta lo más completa posible, a cada uno de estos puntos:

1. ¿Qué espera detectar al observar muestras de agua o de suelo al microscopio?

2. ¿Cómo va a determinar si ha logrado sus expectativas en la observación?

3. Cuál es la fuente de información que fundamenta su observación?

4. Diagrame lo que observa en diferentes aumentos, indicando el aumento del objetivo en el cual realiza la observación y el dibujo correspondiente. 


\section{Bibliografía}

Abric, J. C. (1996) "Specific Processses of Social Representations". Papers on Social Representations, 5 (1), 77-80.

Araya, S. (2002). "Las representaciones sociales: ejes teóricos para su discusión”. Cuaderno de Ciencias Sociales, 127. Costa Rica: Flacso, 84 p.

Banchs, M. A. (2002) “Aproximaciones procesuales y estructurales al estudio de las representaciones sociales". Papers on social representations. Electronic Version, 8. Peer Reviewed Online Journal, 1-15. http://www.swp.uni-linz. ac.at/content/psr/psrindex.htm

Bachelard, G. (1975). La formación del espíritu científico. Buenos Aires: Siglo XXI.

Campanario, J. M. Y Moya, A. (1999) “¿Cómo enseñar ciencias? Las principales tendencias y propuestas”. Enseñanza de las Ciencias. 17 (2), 179-192.

Canghilhem, G. (1971) El conocimiento de la vida. Anagrama.

Carmichael, P., Driver, R., Holding, B., Phillips, I., Twigger, D. y Watts, M. (1990) Research on Students' Conceptions in Science: a Bibliography. Leeds: University of Leeds, Children's Learning in Science.

De Posada, J. M. (1996). “Hacia una teoría sobre las ideas científicas de los alumnos: influencia del contexto". Enseñanza de las ciencias. 14 (3), 303-314.

Díaz De B. J. y Jiménez, A, M. P. (1996). “¿Ves lo que dibujas? Observando células con el microscopio. Enseñanza de las Ciencias. 14 (2), 183-194.

Díaz G. R.; López, R. R. García L. A. Abuín, F. G., Nogueíra, A. E. y García G., J. A. “¿Son los alumnos capaces de atribuir a los microorganismos algunas transformaciones de los alimentos?"
Enseñanza de las Ciencias. 14 (2), 143-153.

Doise, (1982) "L'ancrage dans les études sur les représentations sociales", Bulletin de psychologie. XLV, 405: 189-195. Citado por: Abric, J. C., 1996. "Specific Processses of Social Representations. Papers on Social Representations, 5 (1) 77-80.

Duschl, R. A. (1994). Editorial policy statement and introduction. Science Education. 78 (3), 203-208.

Fisher, K., M. y Moody , D. (2000). "Students misconceptions in biology”. En: Fisher, K., Wandersee, J. y Moody, D. Mapping Biology Knowledge. Kluwer Academic Publishers. Doordrechet, Netherlands.

Giordan, A. (1999). "Representaciones y concepciones”. Currículum Revista de Teoría, Investigación y Práctica Educativa n ${ }^{\circ}$ 6. Http://www.quadernsdigitals.net Consultado sept. 10 de 2005.

Gutiérrez, R. (2005). Polisemia actual del concepto "modelo mental" . Consecuencias para la investigación didáctica. Invetigações em Ensino de Ciências. Porto Alegre, Brazil.

Hierrezuelo, J. Y Montero, A. (1991). La ciencia de los alumnos. Su utilización en la didáctica de la Física y Química. Vélez, Málaga: Elzevir.

Jodelet, D. (1986). “La representación social. Conceptos y teoría”. En: Moscovici, S. (1986) Psicología social, V. II. Pensamiento y vida social. Psicología social y problemas sociales. Madrid: Paidós, pp. 469-494.

Manuel de, B. J. y Grau, S. R. (1996) "Concepciones y dificultades comunes en la construcción del pensamiento biológico". Alambique, 7:53-63. 
Marín, N. "How can we identify replies that accurately reflect students' knowledge? A methodological proposal" En: $J$. Sci. Educ., March, 26 (4), 425-445.

(2003). "Conocimientos que interaccionan en la enseñanza de las Ciencias". Enseñanza de las Ciencias. 2004, 21 (1), 65-78.

Marková, I. (1996) "En busca de las dimensiones epistemológicas de las representaciones sociales". En: Páez, D., Blanco, A. (2002). La teoría sociocultural y la psicología social actual. Madrid, España: Aprendizaje. Citado por: Araya, S. (2002). "Las representaciones sociales: ejes teóricos para su discusión". Cuaderno de Ciencias Sociales, $\mathrm{n}^{\circ}$ 127. Costa Rica: Flacso, 84p.

Moscovici, S. (1985). Psicología social, V. I. Influencia y cambio de actitudes Individuos y grupos. Madrid: Paidós.

Posner, G., Strike, K., Hewson P. y Gertzog, W. (1982). "Accommodation of scientific conception: Toward a theory of conceptual change". Science Education, 66: 211-227.

Pozo, J. I. (1999) "Más allá del cambio conceptual: El aprendizaje de la ciencia como cambio representacional". Enseñanza de las Ciencias. 17 (3), 513-520.

"La adquisición de conocimiento científico como un proceso de cambio representacional". Investigações. Em Ensino de Ciências, 7(3) Dic. Porto Alegre Brazil. http://www.if.ufrgs.br/public/ensino/vol5/n3/v5_n3_a5.htm

Pozo y Carretero (1987). Del pensamiento formal a las concepciones espontáneas, ¿Qué cambia en la enseñanza de las ciencias? Infancia y aprendizaje. 38, 35-52. Citado por: Campanario.
M. y Otero, J. L. 2000. Más allá de las ideas previas como dificultades de aprendizaje: Las pautas de pensamiento, las concepciones epistemológicas y las estrategias metacognitivas de los alumnos de ciencias. Enseñanza de las ciencias. 18 (2), 155-169.

. y Gómez Crespo, M. A. (1998) Aprender y enseñar ciencia. Madrid: Morata.

Rodrigo, M. J.; Rodríguez, A. y Marrero, J. (1993). Las teorías implícitas. Una aproximación al conocimiento cotidiano. Madrid: Visor.

Rodríguez Palmero, M. L. 1997. "Revisión bibliográfica relativa a la enseñanza de la biología y la investigación en el estudio de la célula”. Investigações em Ensino de Ciências, 5 (3) 5 Porto Alegre, Brazil. http://www.if.ufrgs.br/public/ensino/vol5/n3/v5_n3_a5.htm

Schnepps, R. (1997). Minds of our own: lesson fron thin air. [video] Cambridge, Mass. Harvard Univ., Science Media Group. Citado por: Fisher, K. M. The importance of prior Knowledge in College Science Instruction. En: Sunal, D; Wright, E.; Bland, D. Eds. Reform in Undergraduate Science Teaching for the 21 Century. Information Age Publishing Inc. Cap. 5.

Wandersee, J. H. (1995) "Can the history of science help science educators anticipate students' misconceptions?" Journal of Research in Science Teaching, 23 (7), 581-597. Citado por: Rodríguez Palmero, M. L. "Revisión bibliográfica relativa a la enseñanza de la biología y la investigación en el estudio de la célula". Investigações em Ensino de Ciências, 5 (3) 5 Porto Alegre, Brazil. 